\title{
Efficacy of Task Centered Group Work Intervention in Schizophrenia Patients
}

\section{Pankaj Kumar Verma*1 and Suprakash Chaudhury ${ }^{2}$}

${ }^{1}$ Department of Psychiatric Social Work, Ranchi Institute of Neuropsychiatry and Allied Sciences (RINPAS), Kanke, Ranchi, Jharkhand, India ${ }^{2}$ Department of Psychiatry, Rural Medical College, Pravara Institute of Medical Sciences (DU), Loni, Maharashtra, India

\begin{abstract}
Background: Task centered group work is an empirically validated and widely acknowledged problem-solving model of social work that has been applied on variety of client groups across various geographical areas. However, in Indian setting such interventions are deplorably inadequate.
\end{abstract}

Aim: To evaluate the effectiveness of task centered group work intervention on schizophrenia patients in bringing down their sensed psychopathology.

Materials and methods: Thirty schizophrenia patients diagnosed as per ICD-10 DCR by treating psychiatrist were purposively enrolled from RINPAS outpatients department (OPD) and were shared into two groups of consisting of 15 in each group, viz. experimental and control groups. Task centered group work was administered only to the experimental group on twice monthly basis for six months. Pre and post assessments were done using Positive and Negative Syndrome Scale in both the groups.

Results: Majority of the subjects who received task centered group work intervention reported substantial improvement in their perceived psychopathology as compared to subjects in the control group who did not receive such intervention.

Conclusion: Task centered group work intervention was effective in significantly reducing the perceived psychopathology in schizophrenia patients.

Keywords: Task centered group work intervention; Schizophrenia; Positive symptoms; Negative symptoms

\section{Introduction}

Schizophrenia is a complicated cluster of mental illness that includes a range of positive, negative and residual symptoms that alter an affected person's perception, thought, mood and affect and behaviour in a manner that entire domains of his/her personal, social, vocational life get adversely affected by it. Not only the affected person but their caregivers too perceive social isolation, family burden, stigma related to mental illness to a large extent. The disorder often begins in adolescence or early adulthood, between the ages of 15-35 years, which is the most productive period of an individual's life. Men tend to develop its devastating symptoms slightly earlier than women do. Every person affected with this form of mental illness manifests a unique combination of symptoms and experiences that keep him/her entirely apart from normal functioning of life. The reported median incidence rate of schizophrenia from different countries is $15.2 / 100,000$ population and the central $80 \%$ of estimates has ranged from 7.7 to 43.0 per 100,000 populations, and it greatly varies across different geographical regions [1], whereas the global lifetime prevalence of this illness stands at 0.3-0.7 [2]. Even though its incidence rate is quite low but due to its chronic nature schizophrenia often produces significant physical, mental, social impairments not only on its sufferer but equally and sometime even more on their caregivers who are always at high risk to develop emotional problem. Magliano et al. stated that uncertainty about future and comparatively poorer quality of life among its sufferer are most common [3]. Apart from direct cost, schizophrenia also takes a heavy toll on almost all sphere of patients as well as on its caregivers' life including persistent family burden [4], marital adjustment [5], perceived social isolation, shame, discrimination, and stigma [6]. The disease is managed by pharmacotherapy, psychotherapy and other supportive therapies. In clinical social work schemes, the task centered group work (TCGW) intervention is one of them [7].

TCGW was developed in the early 1970s by Reid and Epstein [8] based on Task centered Case Works. This highly structured, timelimited, problem-solving method of intervention focuses on solving problems as clients perceive them. Change in behaviour occurs by tasks, which are activities designed to ameliorate the identified problems. Tasks (activities) are developed from problem-solving activities with clients as well as an array of practice approaches. The focus is on solving the problems on 'here and now'. The popularity of TCGW among direct social work practitioner is due to the fact that it is theoretically open and flexible and thus can be used with many theoretical orientations.

TCGW intervention has been applied in various therapeutic groups with satisfactory outcome [9-18]. However, practical application of group work has not been exercised optimally with Indian population as compared to casework and community work [19]. In view of the dearth of Indian studies in this field, the present work was undertaken to evaluate the effectiveness of TCGW intervention on schizophrenia patients in bringing down their sensed psychopathology

\section{Materials and Methods}

This hospital-based prospective longitudinal study was carried out at Ranchi Institute of Neuropsychiatry and Allied Sciences, Ranchi, India. The protocol of the study was submitted to and approved by the institutional ethical committee.

*Corresponding author: Pankaj Kumar Verma, Ranchi Institute of Neuro-Psychiatry and Allied Sciences (RINPAS), Kanke, Ranchi, Jharkhand, India Tel: + 06512450813; E-mail: papuha2007@yahoo.co.in

Received: May 08, 2017; Accepted: June 06, 2017; Published: June 13, 2017

Citation: Verma PK, Chaudhury S (2017) Efficacy of Task Centered Group Work Intervention in Schizophrenia Patients. J Psychiatry 20: 413. doi:10.4172/23785756.1000413

Copyright: $\odot 2017$ Verma PK, et al. This is an open-access article distributed under the terms of the Creative Commons Attribution License, which permits unrestricted use, distribution, and reproduction in any medium, provided the original author and source are credited 


\section{Inclusion criteria}

- Male patients with age between $18-45$ years.

- Diagnosed by the psychiatrist as Schizophrenia as per the International Classification of Diseases -10 (ICD- 10) - DCR.

- Minimum duration of illness for the past two years and should be availing psychiatric treatments at the OPD level from RINPAS.

- $\quad$ Mild level of severity of illness on PANSS scale.

- Consenting to participate in long-term interventional study.

\section{Exclusion criteria}

- Family history of mental illness.

- Any co-morbid psychiatric illness, substance addiction or physical illness.

- Presence of mental retardation or neurological disorders.

\section{Sample}

A total thirty male schizophrenia patients' as diagnosed by their treating psychiatrist using ICD 10 DCR criteria formed the study sample and were divided into two matched equal groups and henceforth named as experimental and control groups.

\section{Tools}

- Socio-demographic data sheet: A specially designed sociodemographic data sheet including age, sex, marital status, education, economic status, occupation, support system, premorbid adjustment, was prepared for the study.

- Positive and negative syndrome scale (PANSS) for schizophrenia: The PANSS, widely used in research settings, has been developed specifically to assess psychopathology in patients with schizophrenia. This scale is based on the concept that schizophrenia has two distinct syndromes: a positive syndrome including features like delusions and hallucinations and a negative syndrome comprising features like social withdrawal and affective blunting. It has 30 items which are rated on a 7 -point continuum ( $1=$ absent, $7=$ extreme). Ratings are generally based upon information relating to the past week [20].

\section{Procedure}

As per set inclusion and exclusion criteria, patients were selected for the study. Their written informed consent was obtained after explaining the aim and objectives of the study. After gathering sociodemographic information, the PANSS was employed to the patients to obtain baseline scores from experimental and control group patients. Only patients having mild level of severity of illness on PANSS scale were recruited considering the facts that above this range of severity of psychopathology patients might not be co-operative for long-term interventional study and might be reluctant for the interventional study. A TCGW intervention, [11] was applied only to experimental group patients for six months. The tasks selected by the participating patients, ranged from personal problems to interpersonal problems. Following the intervention, post-intervention scores were obtained using the same tools from both the groups.

\section{Results}

Socio-demographic details revealed that in experimental group $12(80 \%)$ were in 20-30 years of age group. Most of the patients were Hindus 12(80\%), belonging to rural areas 10(66.66\%), unmarried $7(46.66 \%)$, educated up to under matric level $8(53.33 \%)$ were unemployed 9(60\%), earning less than Rs.5000 pm 8(53.33\%) and belonged to joint family structure 10(66.66\%). Similarly in control group most of the patients $9(60 \%)$ were in age group of 20-30 years. Most of them were Hindus 11(73.33\%), belonging to rural areas $12(80 \%)$, were unmarried $10(66.66 \%)$, educated up to under matric level $8(53.33 \%)$, were unemployed 10(66.66\%), earning less than Rs.5000 pm income and belonged to joint family structure $8(53.33 \%)$.

Table 1 mentioned paired t-test of positive syndrome score of PANSS of patients of both experimental and control groups' patients. Statistically significant differences emerged in both groups in pre and post with and without intervention conditions both at $\mathrm{p}<0.001$ level reflected in the table. However, there was a significant reduction in mean scores of Positive Syndrome Scores of PANSS were observed in pre-test $(16.07 \pm 1.75)$ and post-test $(12.13 \pm 2.10)$ condition in experimental group whereas in control group patients the mean score of Positive Syndrome Scores of PANSS in pre-test was $(11.40 \pm 2.95)$ and post-test it was $(16.20 \pm 5.83)$.

Table 2 reflected comparison of pre-test and post-test negative syndrome scores of PANSS in patients of experiment and control groups by Paired $t$ test. Statistically significant differences emerged in experimental group score (paired t-test $=4.27, \mathrm{df}=28, \mathrm{p}<0.001$ ) and control group patients (paired t-test $=-3.95, \mathrm{df}=28, \mathrm{p}<0.001$ ). In experimental group the mean score of Negative syndrome score was found decreased in post-test condition whereas in control group it was found increased in post-test condition suggesting worsening of psychopathology.

Table 3 shows the Mean and S.D. and comparison of patients pre-test and post-test general psychopathology scores of PANSS of experiment

\begin{tabular}{|c|c|c|c|c|c|c|c|c|}
\hline Groups $(\mathrm{N}=30)$ & Time point & Mean & 土S.D. & Mean diff. & S.D.diff. & $\%$ of effect & Pairedt test $(\mathrm{df}=28)$ & P-value \\
\hline \multirow{2}{*}{$\begin{array}{l}\text { Experiment } \\
\qquad(n=15)\end{array}$} & Pre-Test & 16.07 & 1.75 & \multirow{2}{*}{3.93} & \multirow{2}{*}{2.19} & \multirow{2}{*}{24.48} & \multirow{2}{*}{6.96} & \multirow{2}{*}{$0.00^{*}$} \\
\hline & Post-Test & 12.13 & 2.10 & & & & & \\
\hline Control(n=15) & Pre-Test & 11.40 & 2.95 & -4.80 & 5.17 & -42.11 & -3.59 & $0.00^{*}$ \\
\hline
\end{tabular}

Table 1: Comparison of patients pre-test and post-test positive syndrome scores of PANSS in experimental and control groups.

\begin{tabular}{|c|c|c|c|c|c|c|c|c|}
\hline Groups(N=30) & Time Point & Mean & $\pm S . D$. & Mean diff. & S.D. diff. & $\%$ of effect & Paired $t(d f=28)$ & P-value \\
\hline \multirow{2}{*}{$\begin{array}{l}\text { Experiment } \\
\quad(n=15)\end{array}$} & Pre-Test & 17.73 & 2.12 & \multirow{2}{*}{5.07} & \multirow{2}{*}{4.59} & \multirow{2}{*}{28.57} & \multirow{2}{*}{4.27} & \multirow{2}{*}{$0.00^{*}$} \\
\hline & Post-Test & 12.67 & 4.15 & & & & & \\
\hline \multirow{2}{*}{$\begin{array}{l}\text { Control } \\
(n=15)\end{array}$} & Pre-Test & 17.27 & 2.25 & \multirow{2}{*}{-6.67} & \multirow[t]{2}{*}{6.53} & \multirow{2}{*}{-38.61} & \multirow{2}{*}{-3.95} & \multirow{2}{*}{$0.00^{*}$} \\
\hline & Post-Test & 23.93 & 5.55 & & & & & \\
\hline
\end{tabular}

Note: * $p<0.001$

Table 2: Comparison of pre-test and post-test negative syndrome scores of PANSS in patients of experimental and control groups. 
Citation: Verma PK, Chaudhury S (2017) Efficacy of Task Centered Group Work Intervention in Schizophrenia Patients. J Psychiatry 20: 413. doi:10.4172/2378-5756.1000413

Page 3 of 3

\begin{tabular}{|c|c|c|c|c|c|c|c|c|}
\hline Groups $(\mathrm{N}=30)$ & Time point & Mean & $\pm S . D$ & Mean diff. & S.D.diff. & $\%$ of effect & Paired $t(d f=28)$ & P-value \\
\hline \multirow{2}{*}{$\begin{array}{l}\text { Experiment } \\
\qquad(n=15)\end{array}$} & Pre- test & 35.00 & 4.50 & \multirow{2}{*}{9.27} & \multirow{2}{*}{4.15} & \multirow{2}{*}{26.48} & \multirow{2}{*}{8.65} & \multirow{2}{*}{$0.00^{*}$} \\
\hline & Post- test & 25.73 & 5.30 & & & & & \\
\hline \multirow{2}{*}{$\begin{array}{c}\text { Control } \\
(n=15)\end{array}$} & Pre- test & 28.20 & 4.99 & \multirow{2}{*}{-11.60} & \multirow{2}{*}{9.16} & \multirow{2}{*}{-41.13} & \multirow{2}{*}{-4.90} & \multirow{2}{*}{$0.00^{*}$} \\
\hline & Post- test & 39.80 & 8.48 & & & & & \\
\hline
\end{tabular}

Note: ${ }^{*} \mathrm{p}<0.001$

Table 3: Comparison of pre-test and post-test general psychopathology scores of PANSS of experimental and control groups.

and control groups in pre and post condition by Paired t test. Statistically significant differences emerged in experimental group patients (paired $\mathrm{t}$-test $=8.65, \mathrm{df}=28, \mathrm{p}<0.001$ ) and control group patients (paired $\mathrm{t}$-test= $-4.90, \mathrm{df}=28, \mathrm{p}<0.001$ ) with respect to general psychopathology score. Mean score of general psychopathology in experimental group had decreased in post intervention condition suggesting improvement in general psychopathology whereas in control group patients it had increased indicating worsening of perceived psychopathology in control group subjects.

\section{Discussion}

The TCGW intervention with mentally ill is like traditional of group work approach of helping patients in which group it self-become mutual aid system for its participating members like self-help group. Group are committed to help each other to short out solutions for their problems in controlled group setting within restricted frame. The participants were encouraged to ventilate their problems and intrusive feelings they were trying to adjust with it. Their problems ranged from hearing some alien voices, low mood and decreased interest in interacting with significant others members, aversion to take psychotropic medicine because of some reasons. This was exercised to clearly define and accomplish the desired tasks within short time frame typically in 12 sessions [11]. Since participants, problems' were more or less homogeneous in nature, thus the homogeneity of the group upraised and reinforced the binding among participants and developed acquaintanceship and trustfulness among participants. The belief that together they can solve their problems in way that is more realistic made them more confidents and strengthened their bonding in therapeutic sessions. Experimental group participants who received TCGW intervention demonstrated better clinical outcome in terms of perceived psychopathology compared to control group participants where no such intervention was imparted. This finding was consistent with previously established studies [3,11]. Most of the tasks were achieved by the patients in every session especially task to insure good drug compliance which was one of the significant determinant. They imitated as well as monitored each other actions in the process of recovery, which ensured good compliance. This might be one of the reasons why many patients reported better clinical outcome on PANSS scale in experimental group which is in tune with previous studies $[14,16]$.

\section{Limitations}

Limitations of the study include the relatively low number of male subjects due to time constraints. The current intervention package required a significant investment of time and human resources to deliver the therapeutic sessions that may not be available in other settings because of the requirement for trained therapist and cost. Future studies should include larger number of patients of both sexes with a longer period of intervention.

\section{Conclusion}

Task centered group work intervention was found effective along with routine psychotropic medication in ameliorating perceived psychopathology in schizophrenia patients. However looking at the small sample size, methodological restrictions, findings of the present study should be, generalize with due caution.

\section{References}

1. McGrath J, Saha S, Chant D, Welham J (2008) Schizophrenia: A concise overview of incidence, prevalence, and mortality. Epidemiol Rev 30: 67-76.

2. Van Os J, Kapur S (2009) Schizophrenia. Lancet 374: 635-645.

3. Magliano L, Fadden G, Economoun M, Held T, Xavier G, et al. (2000) Family burden and coping strategies in schizophrenia: 1- year follow up data from the BIOMAD I study. Soc Psychiatry Psychiatr Epidemiol 35: 109-115.

4. Kumari S, Singh AR, Verma PK, Verma AN, Chaudhury S (2009) Subjective burden on spouses of schizophrenia patients. Industrial Psychiatry Journal 18: 97-100.

5. Muke SS, Ghanawat GM, Chaudhury S, Mishra SK, Verma AN, et al. (2014) Marital adjustment of patients with substance dependence, schizophrenia and bipolar affective disorder. Medical Journal DY Patil Medical University 7: 133138.

6. Shrivastava A, Johnston M, Bureau Y (2012) Stigma of mental illness-1: Clinical reflections. Mens Sana Monographs 10: 70-84.

7. Fortune AE, Mccallion P, Briar-Lawson K (2010) Social work practice for the twenty-first century. Columbia University Press, New York.

8. Reid W, Epstein L (1972) Task centered case work. Columbia University Press New York.

9. Garvin C (1974) Task-centered group work. Social Service Review 48: 494 507.

10. Garvin C (1985) Practice with task-centered groups. In: Fortune AE (ed.), Taskcentered practice with families and groups. Springer, New York. pp: 45-77.

11. Garvin C (1992) A task-centered group approach to work with the chronically mentally ill. Social Work with Groups 15: 67-80.

12. Bielenberg LT (1991) A task-centered preventive group approach to create cohesion in the new stepfamily: A preliminary evaluation. Research on Social Work Practice 1: 416-33.

13. Kinnevy SC, Healey BP, Pollio DE, North CS (1999) Bicycle works: Taskcentered group work with high-risk youth. Social Work with Groups 22: 33-47.

14. Newcome K (1985) Task-centered group work with the chronically mentally ill in day treatment. In: Fortune AE (ed.), Task centered practice with families and groups. Springer, New York. pp: 78-91.

15. Pazaratz D (2000) Task-centered child and youth care practice in residentia treatment. Residential Treatment for Children and Youth 17: 1-16.

16. Pomeroy EC, Rubin A, Walker RJ (1995) Effectiveness of a psych-educational and task-centered group intervention for family members of people with AIDS. Social Work Research 19: 142-152.

17. Woodcock J (1995) Group work using task-centred methods as potential way of helping with maternal depression. J Soc Work Pract 9: 73-84.

18. Lo TW (2005) Task-centered group work. Reflections on practice. International Social Work 48: 455-465.

19. Siddiqui HY (2008) Group work: Theories and practices. Rawat Publications New Delhi.

20. Kay SR, Fiszbein A, Opler LA (1987) The positive and negative syndrome scale (PANSS) for schizophrenia. Schizophr Bull 13: 261-276. 